\title{
Effect of Secondary Task on the Basketball Free Throw Accuracy on Choking under Pressure Skilled players
}

Arsham, S. (Ph.D). Kharazmi University of Tehran, Tehran, Iran Aghaei, M. (M.A). Kharazmi University of Tehran, Tehran, Iran Keshvari, F. (M.A). Kharazmi University of Tehran, Tehran, Iran

Received: $2016-7$ - 19

Accept: $2017-9-3$

\begin{abstract}
The aim of this study was to determine the effect of secondary task relevant and non-relevant to the free throw basketball skill on the free throw accuracy of basketball skilled players in choking under pressure. Twenty right-handed female players (aged 18-30) each with at least three years of experience in basketball took part study after completing the Sport Competition Anxiety Test (SCAT), Annett Handedness Questionnaire (AHQ) and measuring their anthropometric characteristics. The study included two testing sessions with an interval of 2 days. In the first and second session (no-pressure and high pressure, respectively) participants warmed up and performed 10 free throws in three conditions: 1) free throw, 2) free throw with relevant secondary task, 3) free throw with non-relevant secondary task. Results showed that the secondary relevant and non-relevant tasks to free throw have effects on accuracy in no-pressure $(P=0.012, P=0.001)$ and high pressure $(P=0.001, P=0.018)$ conditions. Also, there was significant differences between relevant and non-relevant tasks effects on accuracy in high pressure situation ( $\mathrm{P}=0.001)$.
\end{abstract}

Overall, it may be used the secondary relevant and non-relevant tasks in choking under pressure situations for reduction of pressure imposed on athletes. Also, properly designed secondary tasks for free throw may be used to increase the accuracy of skilled participants under the pressure situations.

Keywords: Pressure, Secondary task, Basketball free throw, Skilled players, Choking 


\section{تأثير تكليف ثانويه بر دقت بر تاب آزاد بسكتبال در شرايط انسداد تحت فشار بازيكنان ماهر}

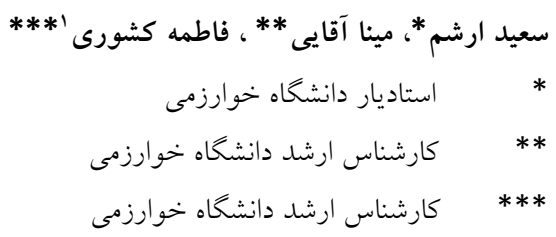

هدف از اين تحقيق تعيين اثرات تكليف ثانويه مرتبط و نامرتبط با مهارت يرتاب آزاد بسكتبال بر دقت يرتاب بازيكنان

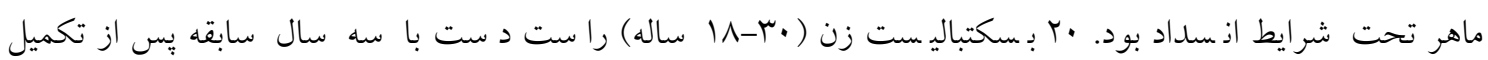

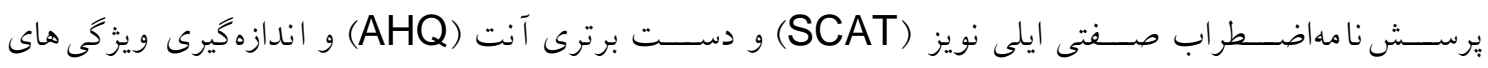

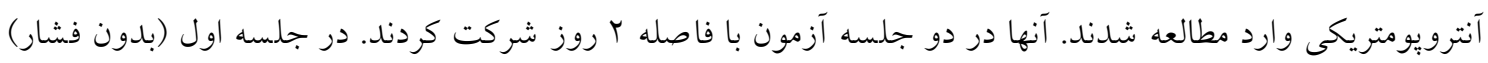

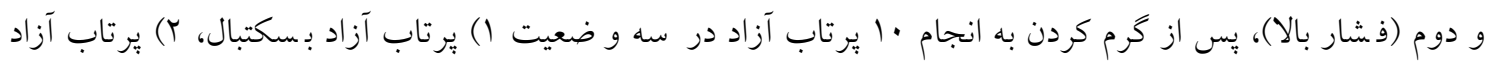

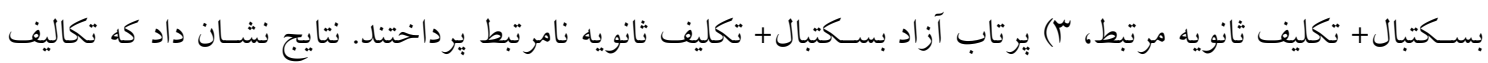

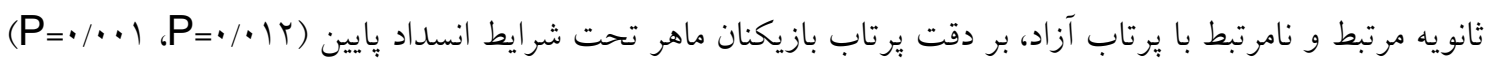

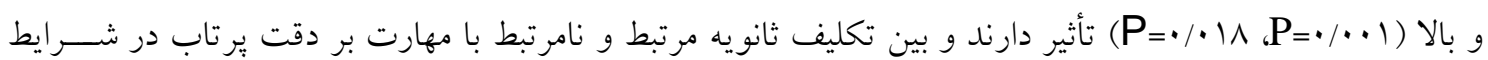

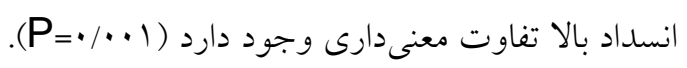

به طور كلى، براى كاهش فشـار وارده بر ورزشـكاران در شــايط انسـاد مىتوان از تكاليف ثانويه مرتبط و نامرتبط و

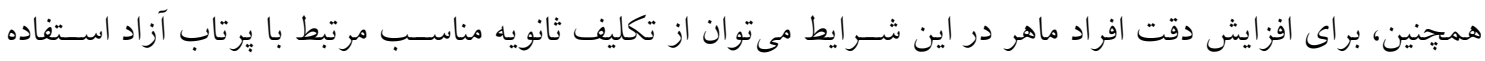


در سالهاى اخير تحقيقات بسيارى اثرات تمركز توجه بر عملكرد را نشان دادهاند؛ نتايج حاصل از آنها نشان دادهاند كه تخصيص منا سب منابع توجه باعث بهبود يادگيرى و عملكرد حركتى مى شود (1). ولف و همكارانش (1) (1) براى تو ضيح برترى اثرات

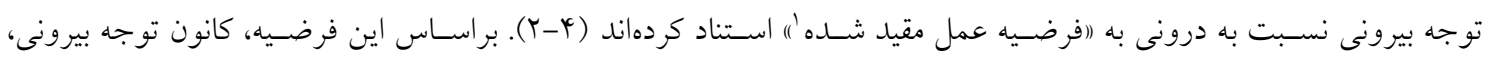

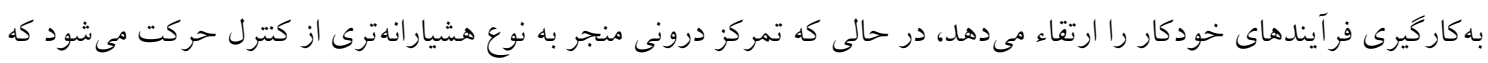

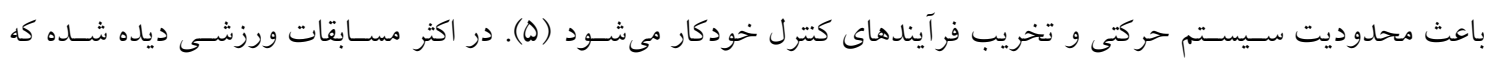
بازيكنان حرفهاى در لحظات حسـاس بازى نمى توانند سـادهترين مهارتها را انجام دهند و باعث مىشـوند تيمشـان امتيازى به

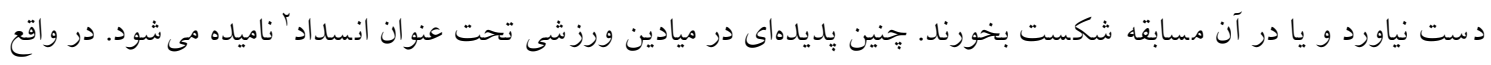

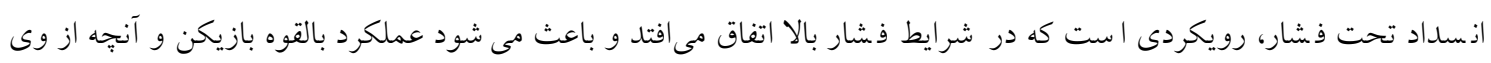

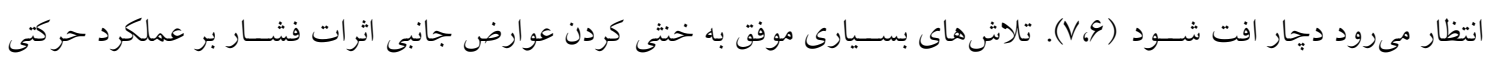

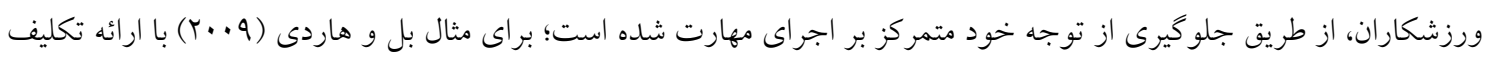

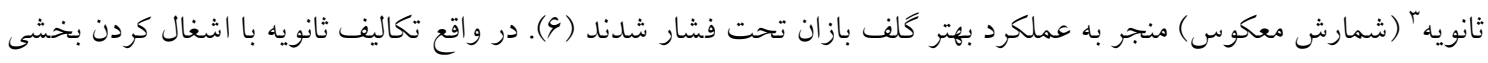

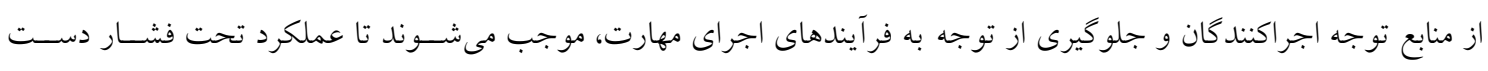

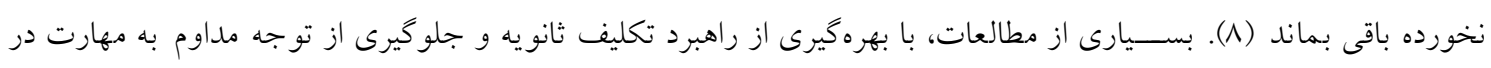
اجراهاى حركتى، موفق به ختى كردن تأثيرات منفى فشار بر عملكرد خودكار شدهاند (•)، (9). در واقع، ضمن استفاده از تكاليف

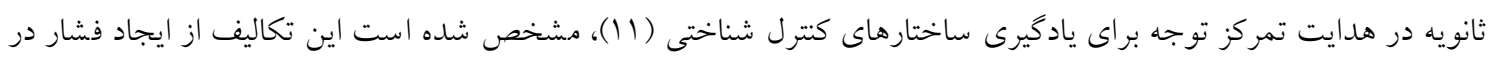

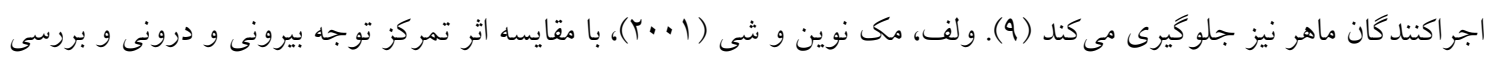
فر ضيه عمل مقيد شده، اظهار دا شتند كه واكنش سريع به تكليف ثانويه حاكى از كاهش بار توجه در شرايط اتخاذ تمركز توجه بيرونى است و در نتيجه به نظر مىرسد تكليف حركتى در وضعيت اتخاذ تمركز توجه بيرونى با خودكارى بيشترى انجام شده و

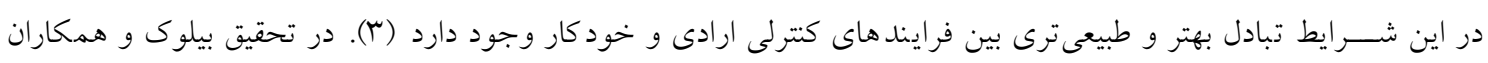

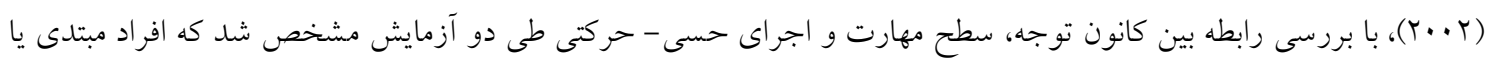
افراد با سطوح بايين مهارت در شرايط كانون توجه درونى بهترند، اما اجراى افراد ماهر در اين شرايط مختل مى شود (Y) (I). مولن

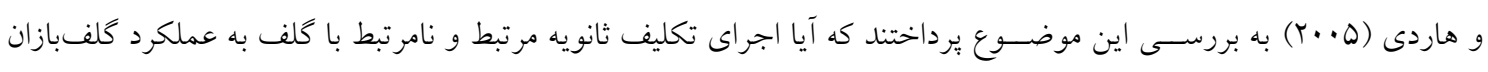

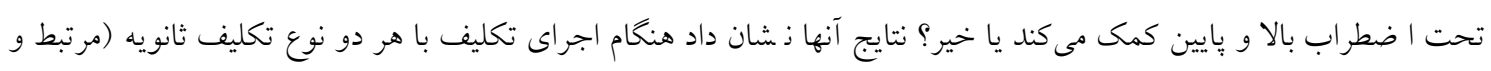

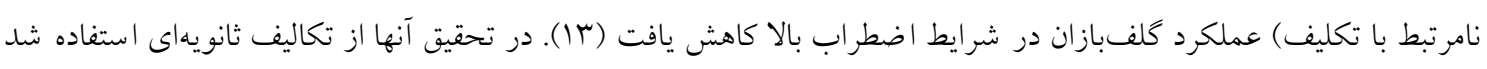

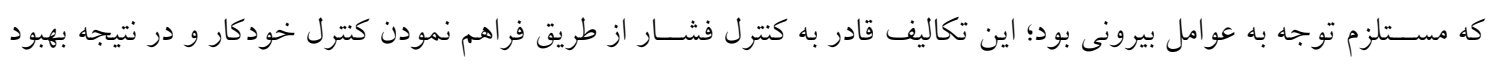
عملكرد نشد و نتيجه كيرى كردند كه تكليف ثانويه از هر نوع (مرتبط يا نامرتبط)، نقشى در كنترل شناختى عملكرد و جبر بران فشار

$$
\text { و اضطراب تحميل شده بر تكليف ندارد. }
$$

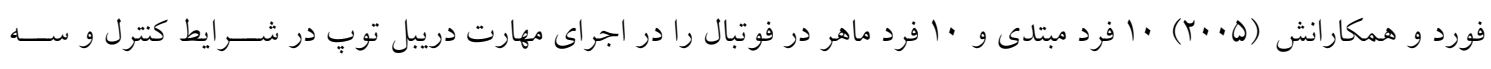
وضعيت كانون توجه بيرونى (تكرار كلماتى كه در زمان اجراى مهارت شنيده مى شد)، كانون توجه درونى مرتبط (تمركز بر بيا) و كانون توجه درونى غير مرتبط (تمركز بر بازو) مقايسه كردند. آنها يافتهاى خود را كواهى بر درستى فرضيه اختلال در خودكارى

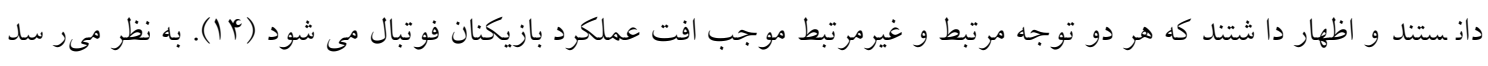

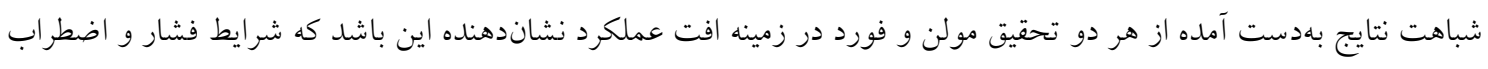
بالا باعث گرديده تا اثرات سـودمند توجه بيرونى در هر دو تكاليف ثانويه مرتبط و نامرتبط به نحوى خنثى گردد. بيشــنهاد فورد

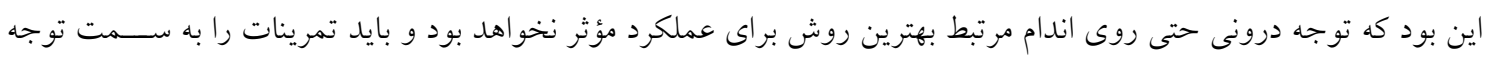
بيرونى سوق داد اما مرتبط بودن يا نبودن تكليف ثانويه آن بايد دوباره در شرايط واقعى ترى در افراد ماهر مورد بررسى قروار كيرد. 


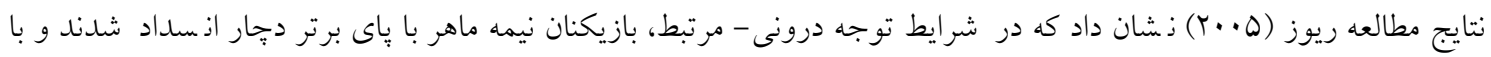

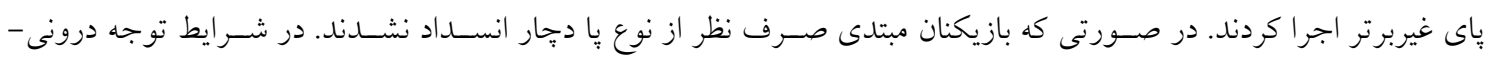

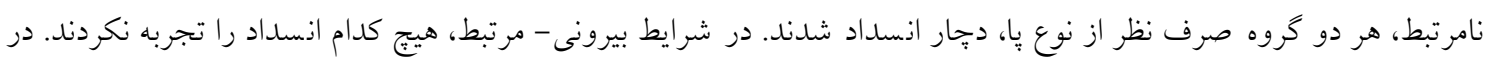

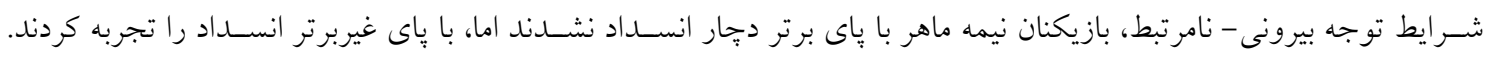

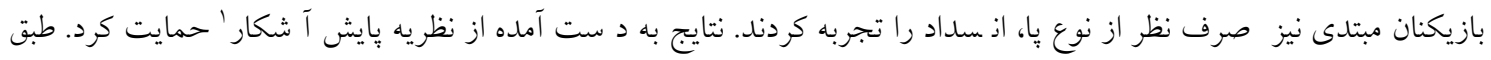

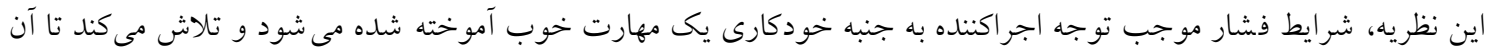

را كنترل نمايد (A). (1)

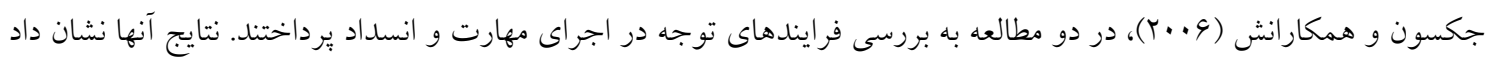

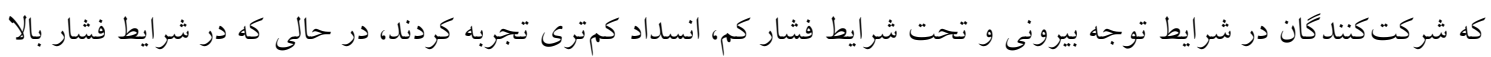

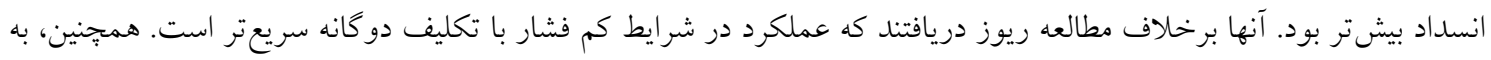

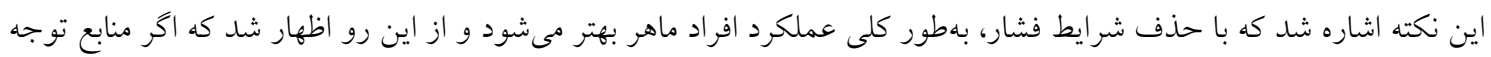

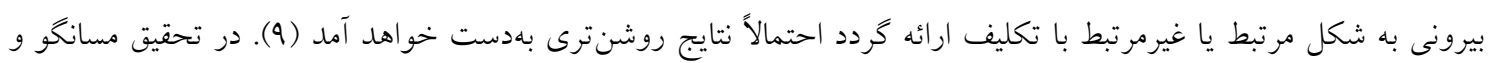

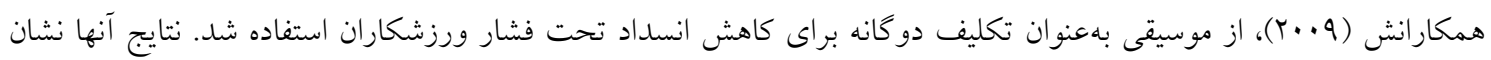

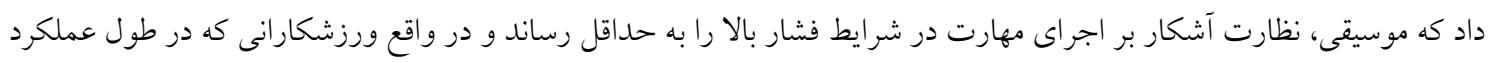

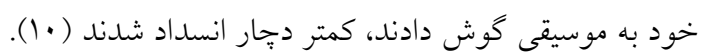

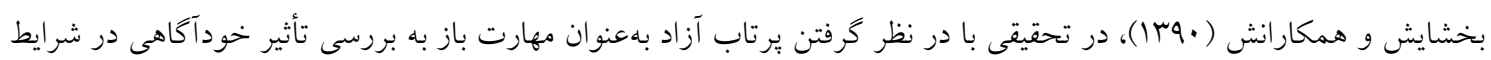

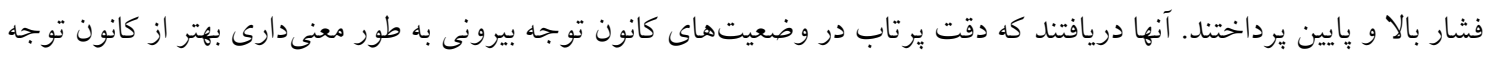

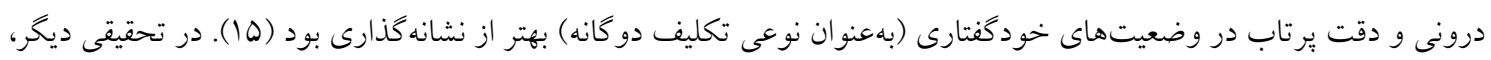

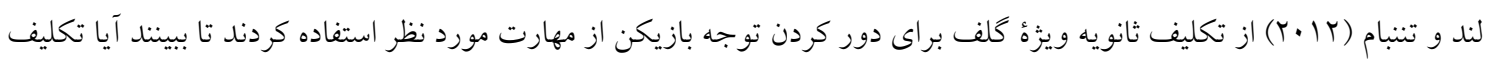

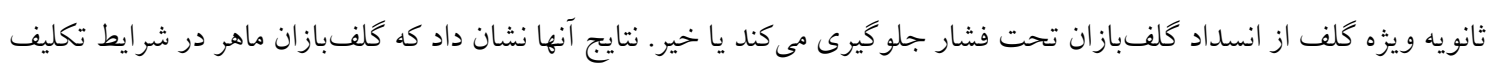

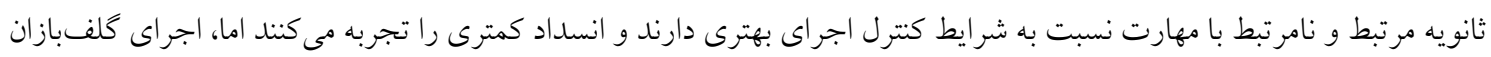

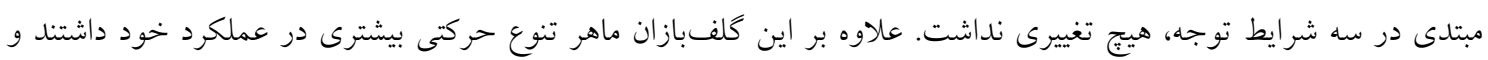

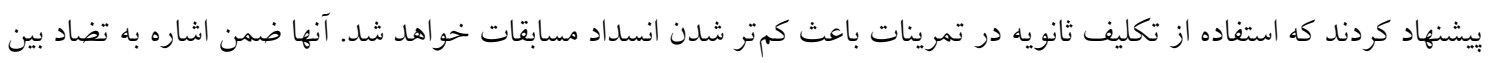

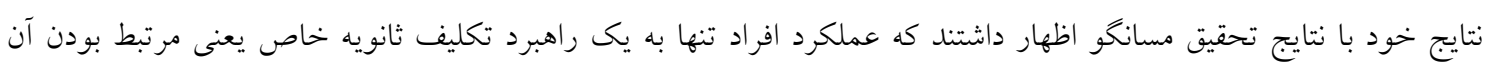

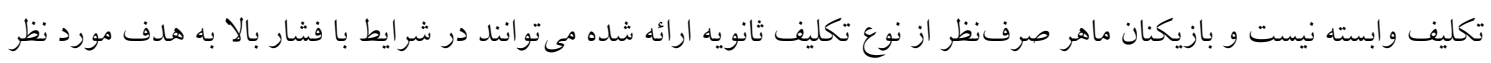

دست يابند (19).

فتحى خامنه (Y (1) اثر منبع كانون توجه نشانههاى كلامى بر انسداد دختران نوجوان مبتدى را هنغام يرتاب آزاد بسكتبال تحت

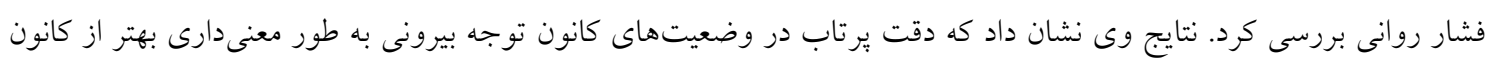

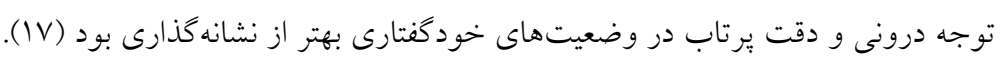

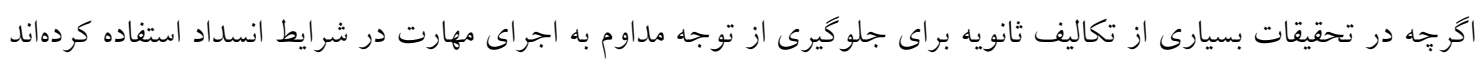

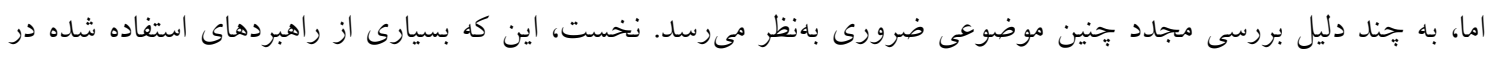

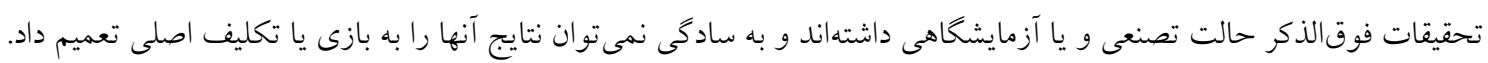

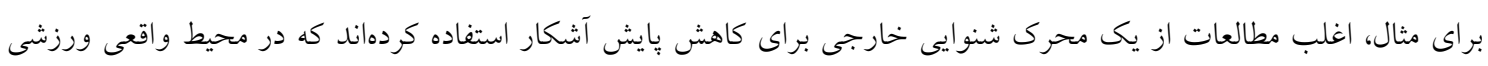

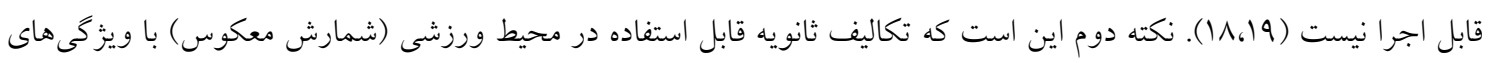

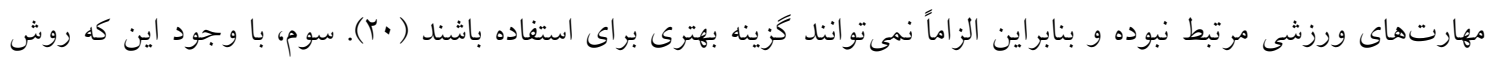

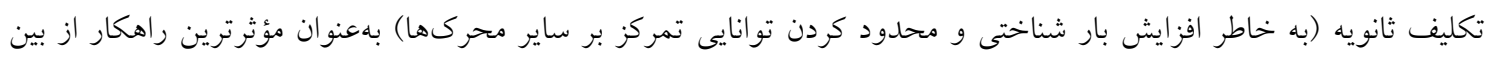

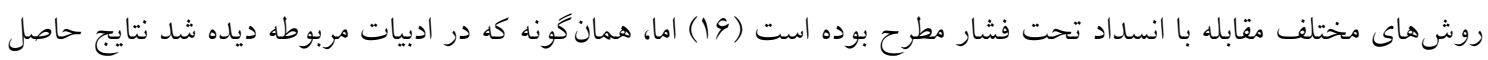


از تحقيقات در هنكام استفاده از اين شيوه متناقض بوده است و هنوز جندان واضح نيست كه اكر تكليف ثانويه مرتبط يا غيرمرتبط

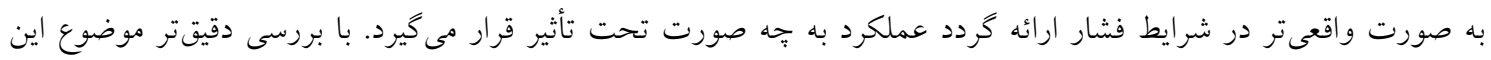

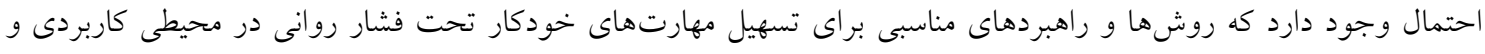

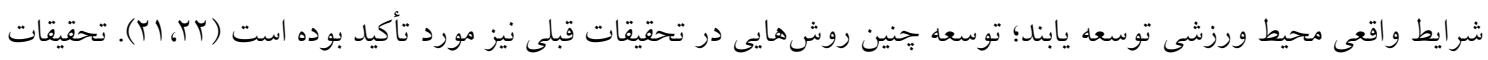

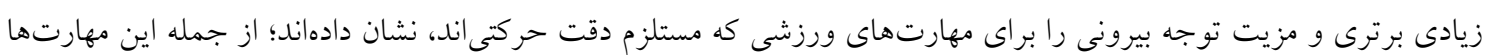

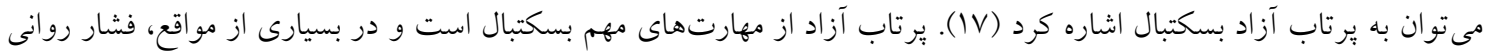
كه به فرد يرتاب كننده وارد مىشود باعث از دست رفتن امتياز حتى در افراد بسيار ماهر مىشود. از آنجا كه تحقيقى در راستاى

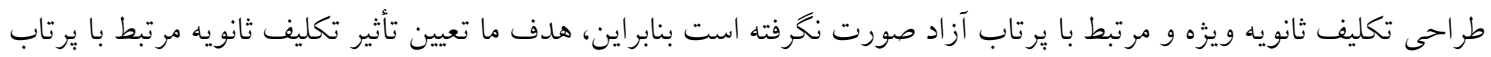

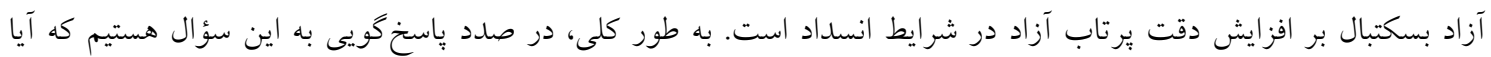

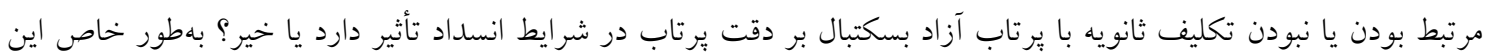

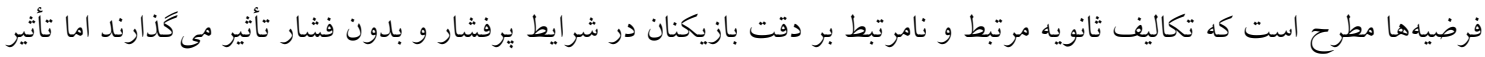
آنها متفاوت است.

\section{روش تحقيق}

اين تحقيق از نوع ميدانى و با روش نيمه تجربى (بدون كروه كنترل) است كه تأثير تكليف ثانويه بر دقت يرتاب آزآن باد بسكتبال در

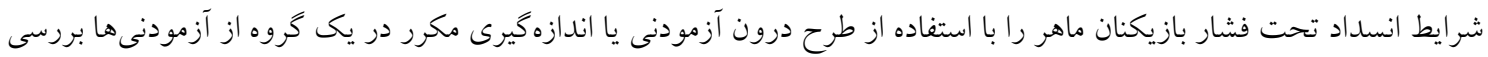

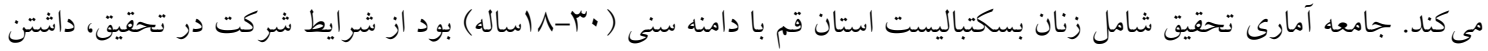

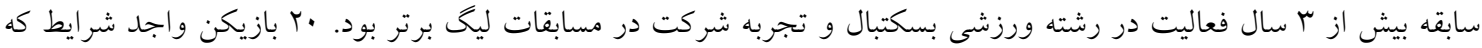

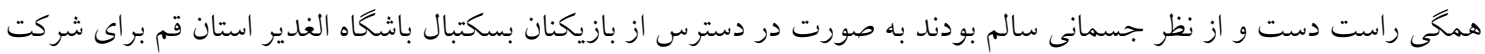

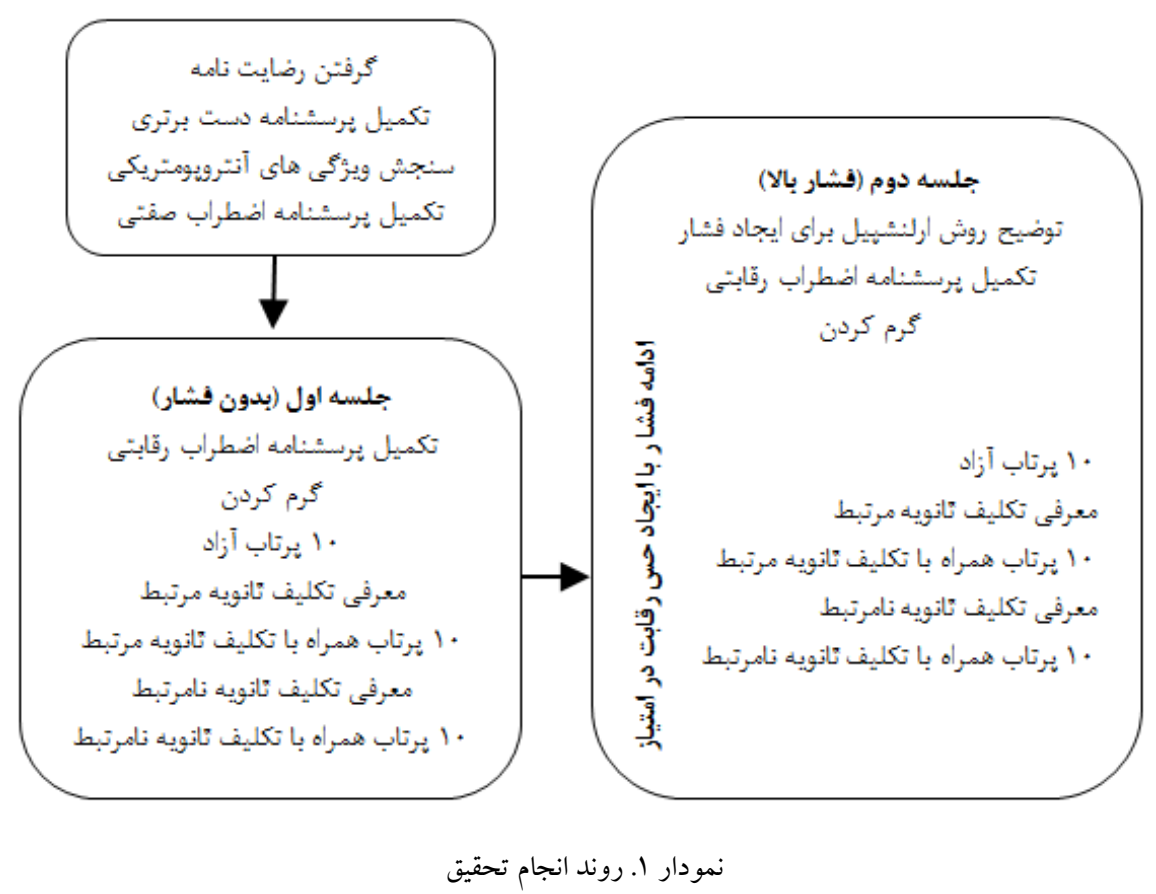


همانكونه كه در نمودار ا نشان داده شده است، يّ از ارايه توضيحات مختصر به ورزشكاران در رابطه با موضوع، از همه آنها

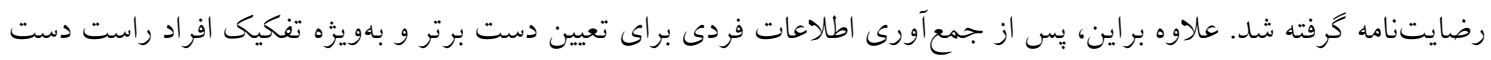

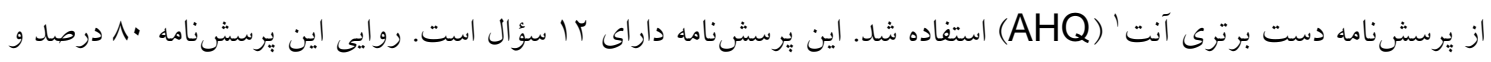

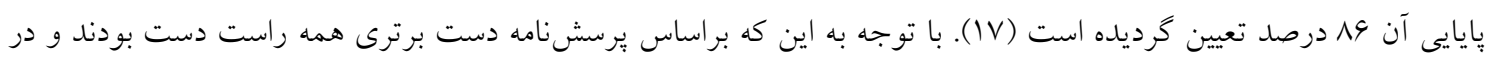

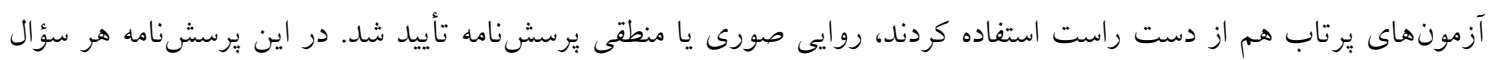

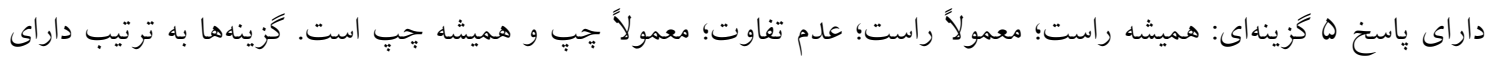

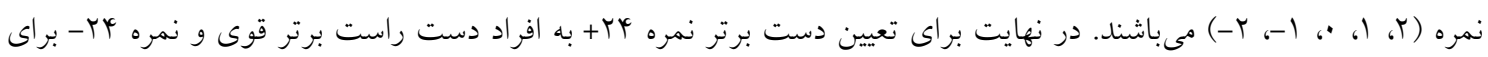

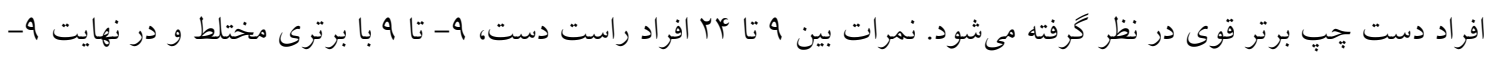

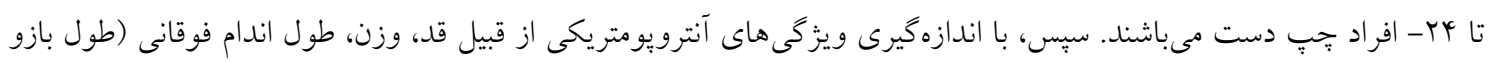

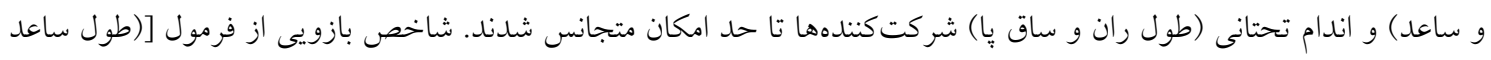
تقسيم بر طول بازو) × × ‥

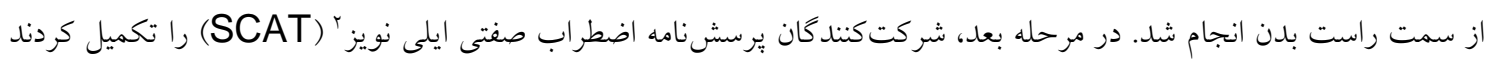

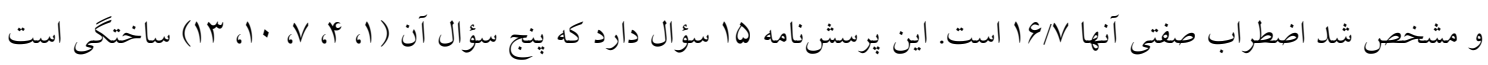

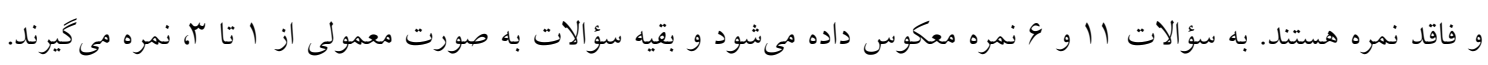

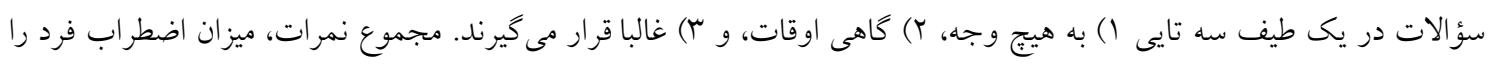

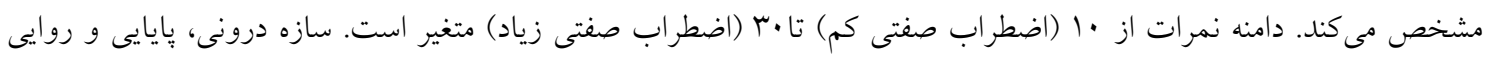

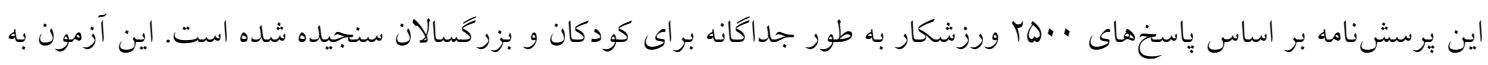

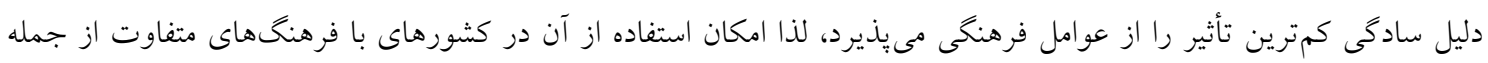

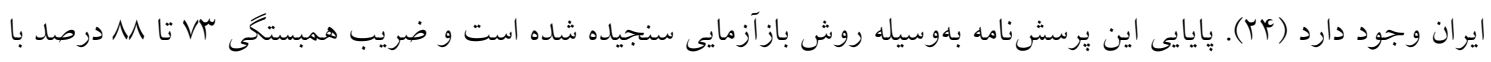

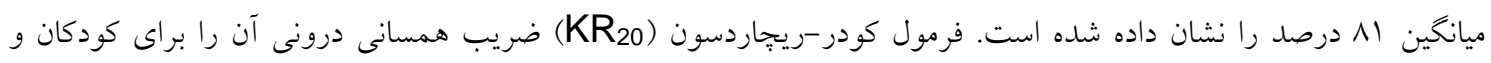

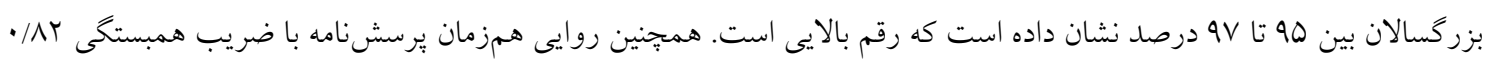

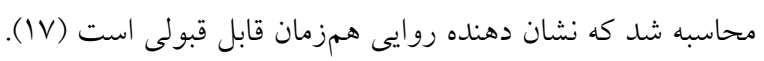

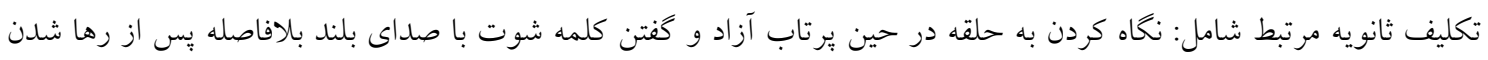

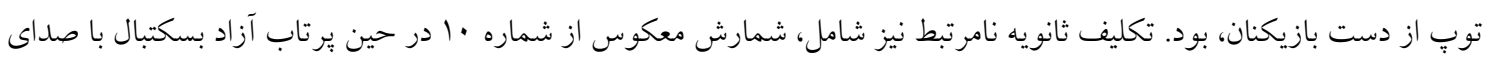

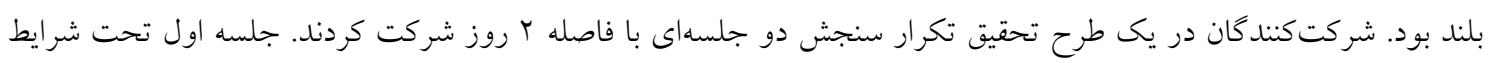

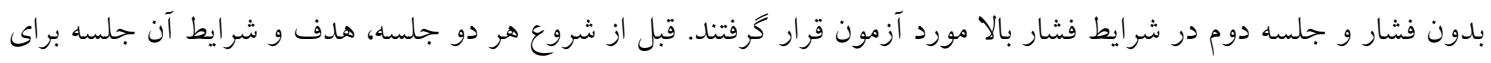

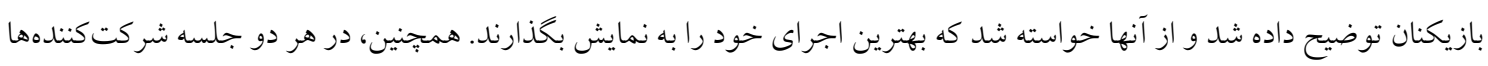

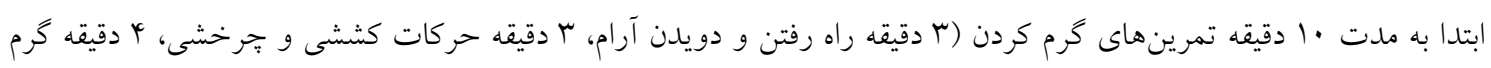
كردن با توب) را انجام دادند.

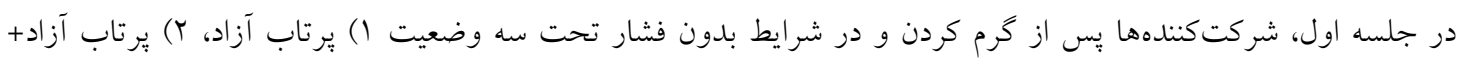

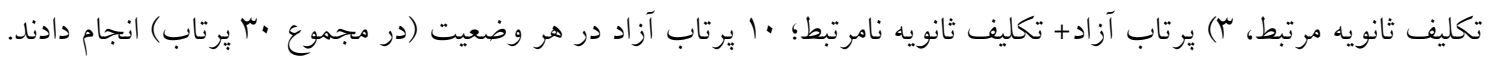

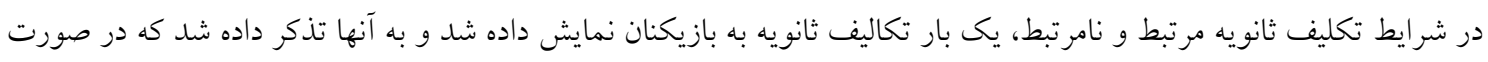

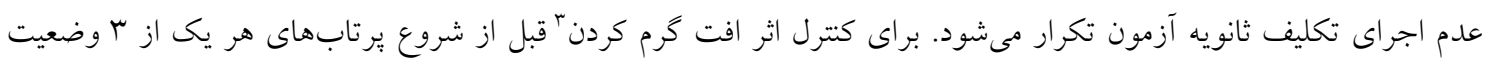

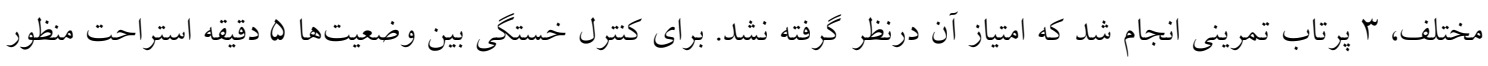

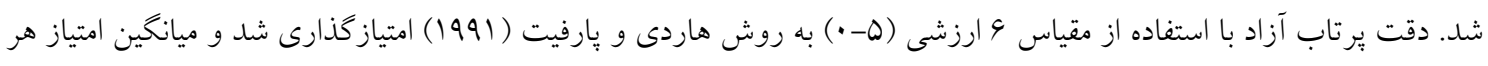

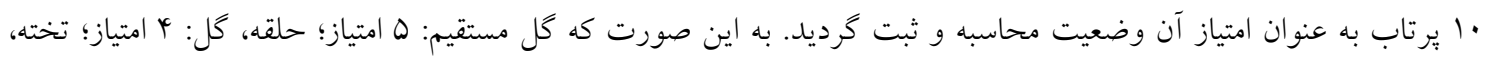




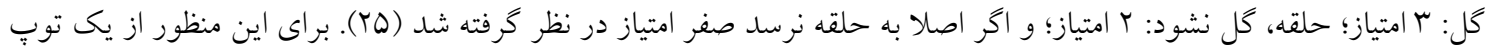

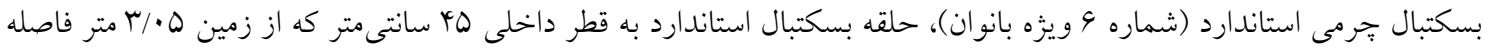

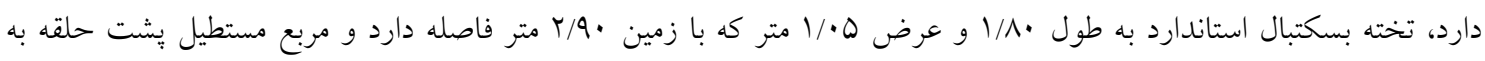
طول ه9 و عرض هأ سانتى متر رسم شده، استفاده شد.

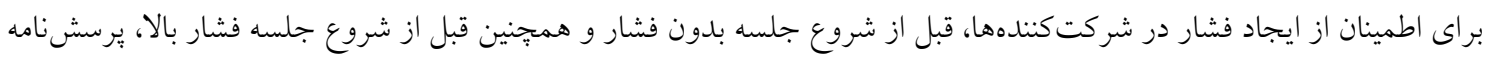

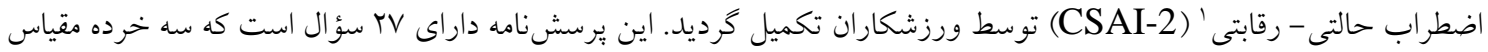

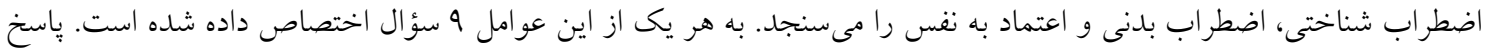

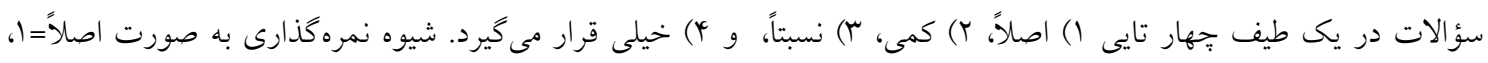

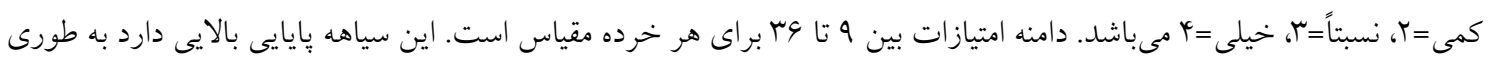

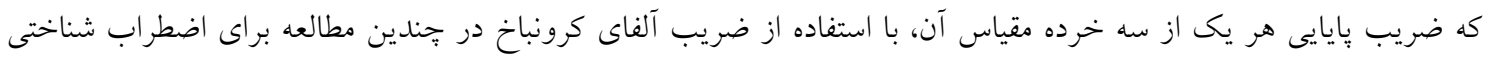

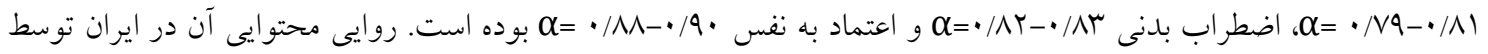

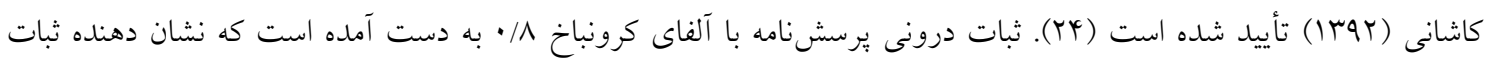

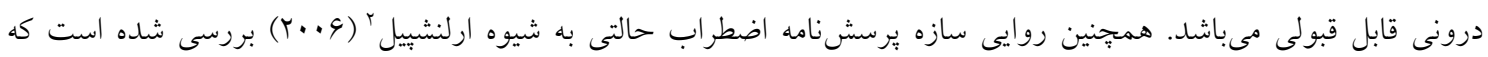

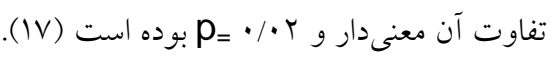

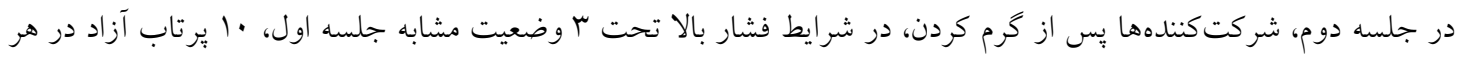

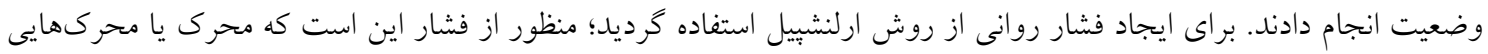

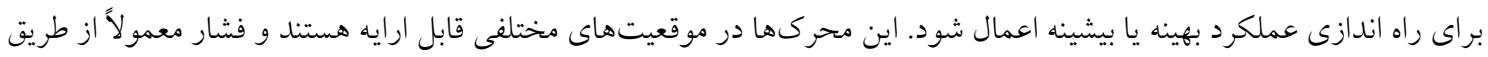

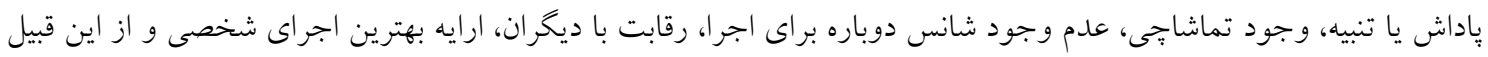

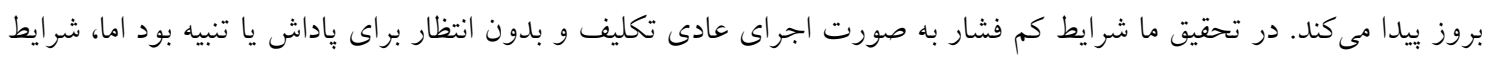

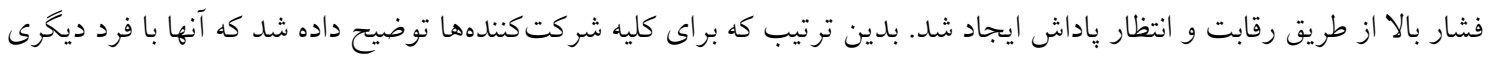

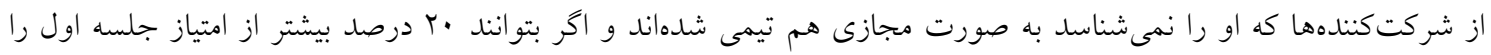

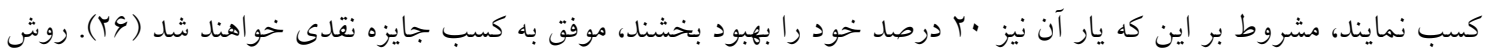

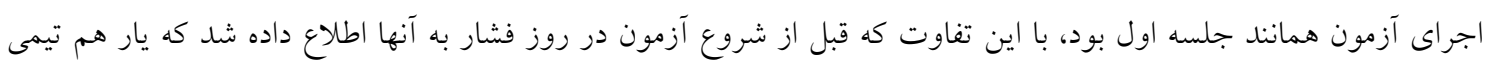

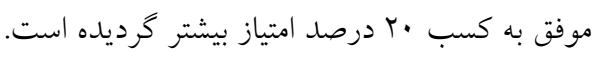

\section{روش آمارى}

علاوه بر آمار توصيفى، در بخش آمار استنباطى براى اطمينان از طبيعى بودن توزيع دادهها از آزمون شاييرو ويلك و براى آزمون

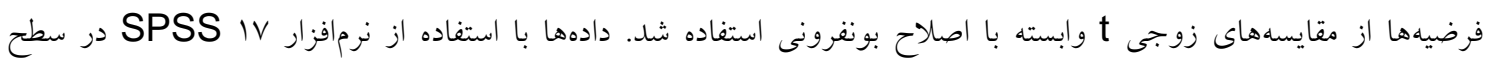

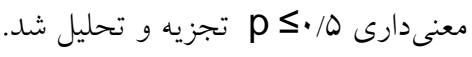

جدول ا، اطلاعات توصيفى (ميانخين و انحراف معيار) مربوط به قد، وزن، اضطراب صفتى، شاخص بازويى و شاخص رانى آزمودنىها را نشان ميدهد. 
جدول ا. ميانگين و انحر اف معيار سن، قد، وزن، اضطراب صفتى، شاخص بازويى و شاخص رانى آزمودنىها

\begin{tabular}{|c|c|c|}
\hline انحر اف معيار & ميانكين & متغير \\
\hline$r / 11$ & $r \mu / \mu$. & سن (سال) \\
\hline $9 / 99$ & $194 / V 0$ & قد (سانتى متر) \\
\hline$r / 19$ & $91 / T 0$ & وزن (كيلوكرم) \\
\hline $1 / \wedge 9$ & $19 / \mathrm{V}$. & اضطراب صفتى \\
\hline $1 / 40$ & $V I / K Y$ & شاخص بازويى \\
\hline$T / T Q$ & $9 Y / V Y$ & شاخص رانى \\
\hline
\end{tabular}

در جدول ا، ميانخين سن، قد، وزن، اضطراب صفتى، شاخص بازويى و شاخص رانى آزمودنىها ارايه شده است. اين اعداد نشاندهنده ميزان تناسب و براكندكى متغيرهاى مزبور مىباشد. همجنين، بيشترين و كمترين براكندكى به ترتيب با مقادير 9/99 و 1/1/ مربوط به متغيرهاى قد و شاخص بازويى است. در جداول زير نتايج مقايسههاى زوجى t وابسته با اصلاح بونفرونى براى آزمون فرضيهها و مقايسه بين اثرات تكليف ثانويه مرتبط و نامرتبط در دو شرايط فشار بالا و پيايين بر دقت برتاب آزاد ارايه شده است. جدول r. مقايسه ميانگين نمره دقت در دو شرايط انسداد بايين و بالا براى وضعيتهاى يرتاب آزاد با تكليف ثانويه مرتبط، يرتاب آزادو بر تاب آزاد با تكليف ثانويه نامرتبط

\begin{tabular}{|c|c|c|c|c|c|c|}
\hline $\mathbf{P}$ & \multicolumn{2}{|c|}{$\mathbf{T}$} & انحر اف معيار & 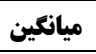 & وضعيت & شرايط \\
\hline.$/ .14$ & & \multirow{2}{*}{$11 / 11$} & $M T / T$ & $K r / A$. & يرتاب آزاد با تكليف ثانويه مرتبط & \multirow{3}{*}{ انسداد بايين } \\
\hline \multirow{2}{*}{$\cdot \cdots 1$} & \multirow{2}{*}{$\Lambda / 4}$. & & $r / \Lambda K^{k}$ & $M T / T \Delta$ & فقط يرتاب آزاد & \\
\hline & & & 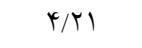 & $r v / 4$. & يرتاب آزاد با تكليف ثانويه نامرتبط & \\
\hline$\cdot \cdots 1$ & \multirow[t]{2}{*}{ IV/Ar } & & $r / 9$. & $4+/ 90$ & يرتاب آزاد با تكليف ثانويه مرتبط & \multirow{3}{*}{ انسداد بالا } \\
\hline \multirow{2}{*}{.$/ \cdot 11$} & & \multirow{2}{*}{$19 / 91$} & r/GT & $r \cdot / \Delta$ & فقط يرتاب آزاد & \\
\hline & & & T/Vq & MN/lQ & يرتاب آزاد با تكليف ثانويه نامرتبط & \\
\hline
\end{tabular}

همانطور كه جدول r، نشان مىدهد در شرايط انسداد يايين، تفاوت بين ميانخين نمره دقت يرتاب آزاد با تكليف ثانويه مرتبط و

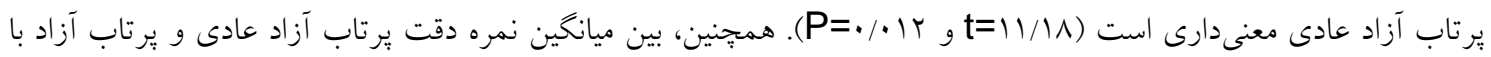
تكليف ثانويه نامرتبط تفاوت معنى دارى وجود دارد ( • t در شرايط انسداد بالا، تفاوت بين ميانكين نمره دقت يرتاب آزاد با تكليف ثانويه مرتبط و يرتاب آزاد عادى معنىدارى است

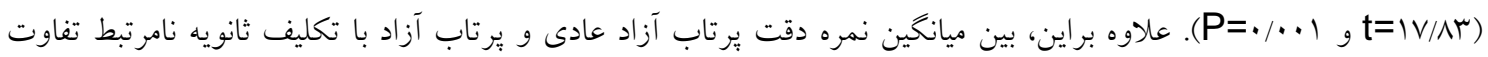

$$
\text { معنى دارى وجود دارد (P= (P) }
$$

جدول r. نمره دقت در دو وضعيت يرتاب آزاد با تكليف ثانويه نامرتبط و برتاب آزاد با تكليف ثانويه مرتبط در شرايط انسداد بالا

\begin{tabular}{|c|c|c|c|c|c|}
\hline$P$ & $\mathrm{~T}$ & انحراف معيار & ميانكين & 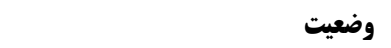 & \\
\hline \multirow{2}{*}{$\cdot \cdots 1$} & \multirow{2}{*}{$9 / 99$} & r/Vq & rN/lQ & يرتاب آزاد با تكليف ثانويه نامرتبط & \multirow{2}{*}{ انسداد بالا } \\
\hline & & $r / 9$. & $4+/ 90$ & يرتاب آزاد با تكليف ثانويه مرتبط & \\
\hline
\end{tabular}


همانطور كه جدول r،، نشان مىدهد در شرايط انسداد بالا، بين ميانگين نمره يرتاب آزاد در دو وضعيت با تكليف ثانويه نامرتبط

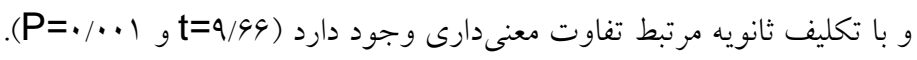

\begin{tabular}{|c|c|c|c|c|}
\hline $\mathbf{P}$ & $T$ & انحراف معيار & ميانكين & سنجش فشار \\
\hline \multirow{2}{*}{$\cdot / \cdot r$} & \multirow{2}{*}{$1 / 94$} & $r / r$ & $r \mu / \Lambda$. & اضطراب حالتى رقابى قبل از جلسه اول \\
\hline & & $r / 9$. & $\mu / 90$ & اضطراب حالتى رقابتى قبل از جلسه دوم \\
\hline
\end{tabular}

بر اساس نتايج جدول عا، بين ميانخين نمره اضطراب حالتى رقابتى آزمودنىها قبل از جلسه اول و قبل از جلسه دوم تفاوت معنى دارى وجود دارد (

\section{بحث و نتيجه}

هدف اصلى اين تحقيق تعيين تأثير تكليف ثانويه (نامتبط و مرتبط با مهارت) در شرايط انسداد (يايين و بالا) بر دقت برتاب آزاد

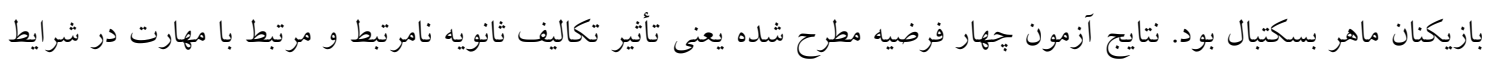

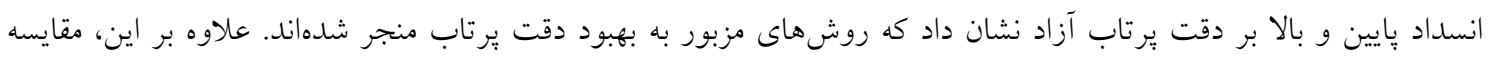

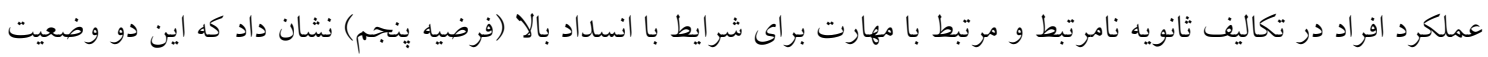

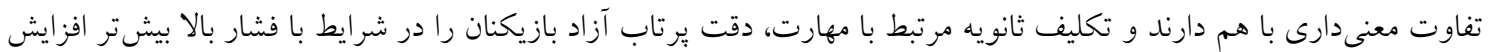

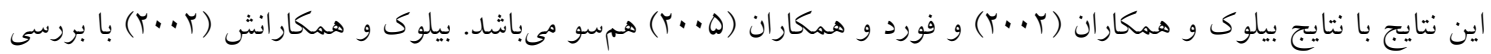

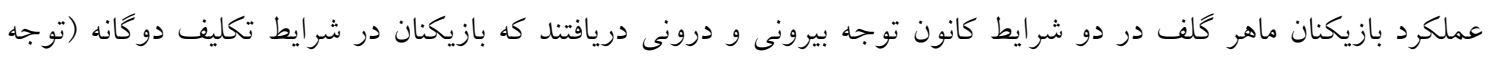

بيرونى) اجراى دقيقترى داشتهاند (r) (I).

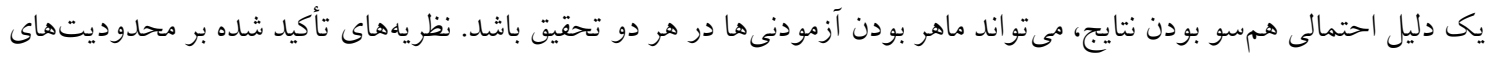

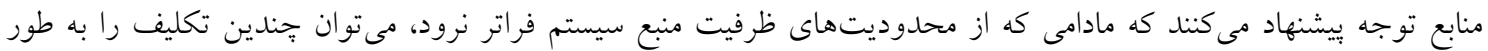

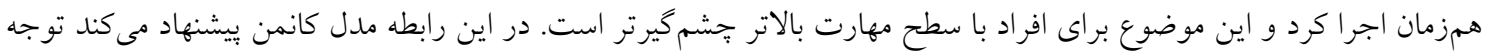

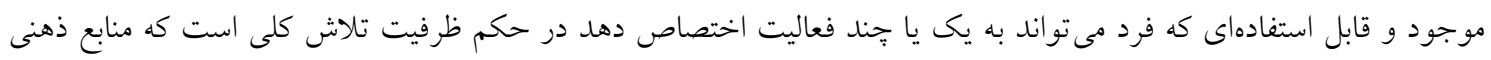

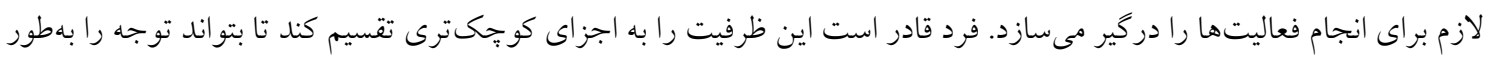

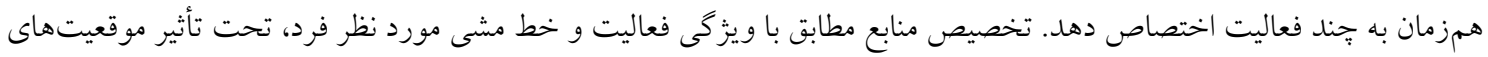

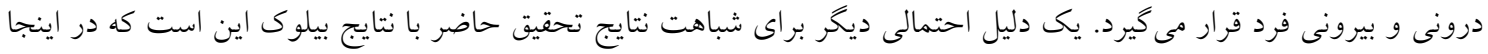

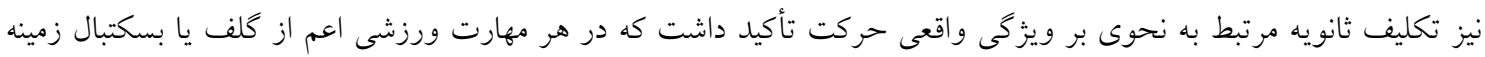

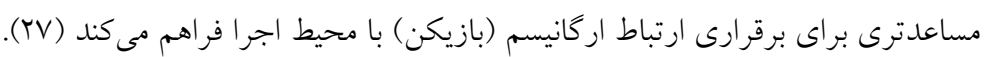

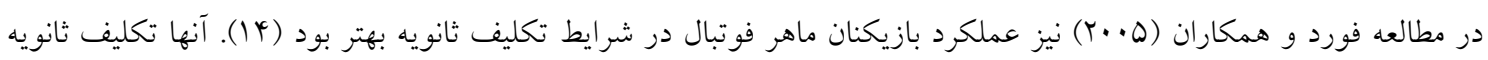

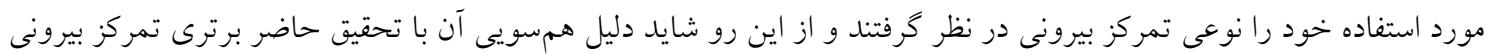

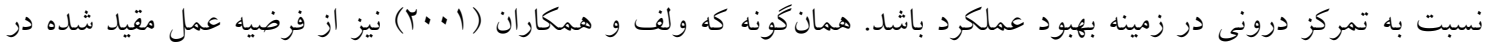
توضيح برترى اتخاد تمركز توجه بيرنى نسبت به درونى استفاده نمودهاند، در زمان اتخاذ تمركز توجه درونى، فرد باد با تلاش هشيارانه

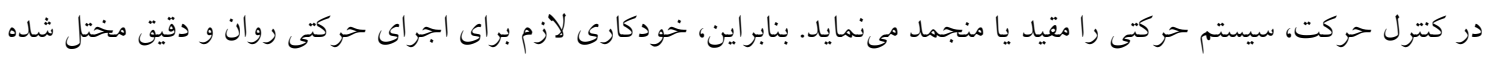

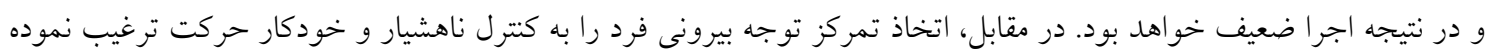
و اجراى بهترى را نمايش خواهد كَاشت (با، بان). 


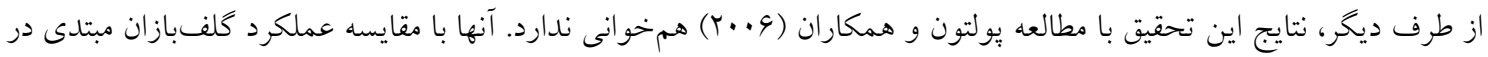
دو شرايط متفاوت تمرين با دستورالعمل كانون توجه بيرونى (تكليف ثانو يه) و درونى دريافتند كه عملكرد افراد در شرايط تمركز

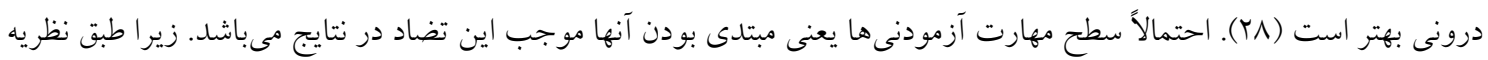
يردازش كنترل شده، بردازش اطلاعات جندين فعاليت مجزا به صورت موازى انتخاب نمىشوند و نيازمند تلاش است و اين روند بهويزه در تكاليفى رخ مىدهد كه به خوبى آموخته نشده و يا براى اجراكننده جديد باشند. اجراى دو تكليف بهطور همزمان كه هر ير دو به بردازش كنترل شده نياز داشته باشند، مىتواند سبب افزايش بار اطلاعات و ايجاد اختلال در اجراى فرد در يكى يا هر دو تكليف شود. در تحقيق يولتون عملكرد ضعيف گروه با شرايط تكليف ثانويه را مىتوان به افزايش بار توجهى نسبت داد كه به دليل

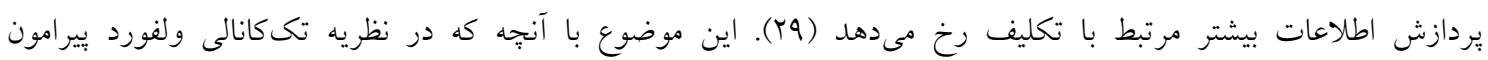

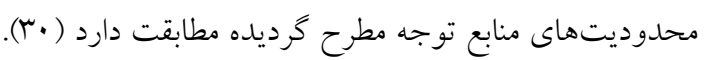

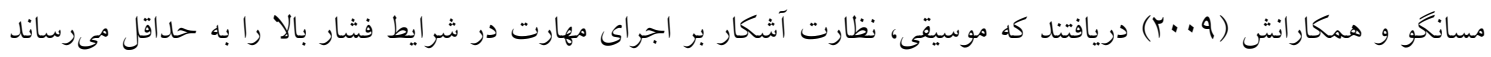
(•). به عقيده آنها استفاده از تكليف شناختى براى كاهش انسداد مىتواند به نحوى بر عملكرد تأثير مثبت داشته باشد و احتمالاً همين موضوع دليل همسو بودن آن با اين تحقيق مىباشد زيرا، در تحقيق حاضر تأثير معنى دار تكليف ثانويه نامرتبط بر دقت برتاب آزاد و بهبود آن در شر ايط انسداد بالا نشان داده شد. اما، در خصوص دئ برترى تكليف ثانويه مرتبط نسبت به تكليف ثانويه نامرتبط كه در فرضيه ينجم اين تحقيق مشخص شد، جكسون و همكاران (4. (Y) در مطالعه خود روى بازيكنان هاكى و فوتبال به نتايج

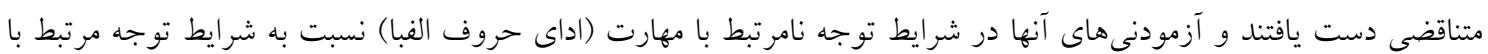
مهارت (تكليف تمركز بر حركت اندام)، اجراى بهترى داشتند (9). آنها اظهار داشتند كه تمركز توجه بيرونى براى شنيدن الفبا و

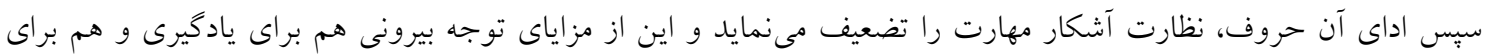

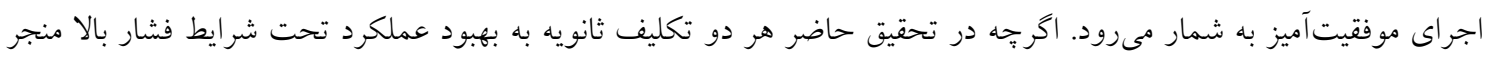

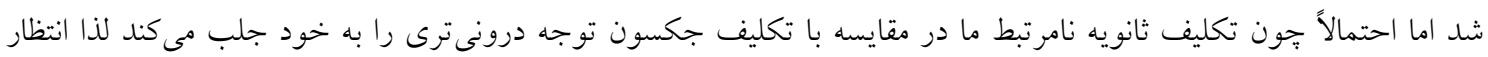
جنين تفاوتى وجود دارد. در تحقيق آنها آزمودنى مىبايست قبل از اداى حروف الفبا حتماً به محرى مشابه بيرونى توجه بيشترى جلب مى كرد در حالى كه تكليف شمارش معكوس تحقيق حاضر فقط توسط خود فرد راهاندازى مىشد. اين موضوع با نظريه باز گمارى' كه بيان مىدارد افراد در مواجهه با فشار به سطوح قبلى بردازش برمى گردند و هنخام بازگشت فرد به نوعى كتترل

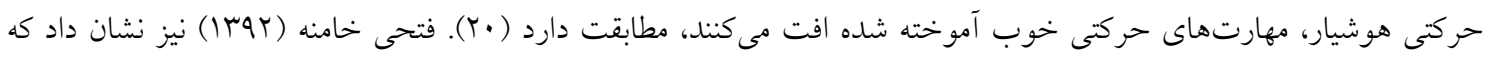
دقت يرتاب در وضعيتهاى كانون توجه بيرونى به طور معنىدارى بهتر از كانون توجه درونى و دقت يرتاب در وضعيتهاى

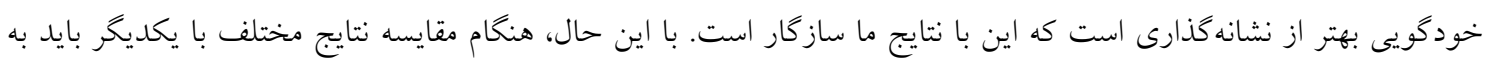

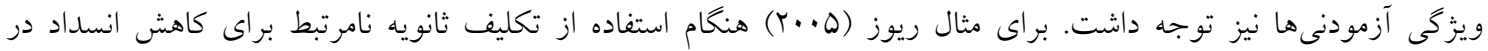
فوتباليست هاى نيمه ماهر و مبتدى دريافت كه هر دو گروه شركت كنند كان دجار انسداد شدند (^) كه اين با يافتهاى تحقيق حاضر در تضاد است. ريوز سطح مهارت يعنى مبتدى و ماهر بودن را بهعنوان يك عامل مهم تأثيريذيرى عملكرد از تكليف ثانويه (مرتبط يا نامرتبط) قلمداد كرد. در تحقيق بخشايش و همكاران (•وس (1) بيرامون تأثير خودآكاهى و توجه بر عملكرد تحت شر ايط انسداد نيز مشخص شد كه توجه نامرتبط به مهارت در شرايط فشار بالا همراه با خودآكاهى، موجب افت عملكرد بيشترى شده است. آنها اظهار داشتند كه با افزايش سطح انخيختكى، توجه فرد فقط به نشانههاى مربوط معطوف شده و از عوامل نامربوط صرفنظر مى شود

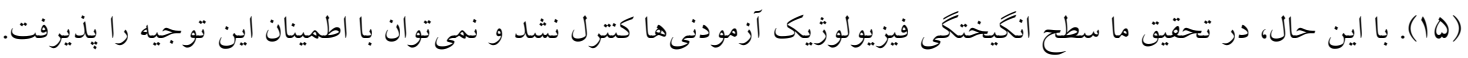
از شواهد ديخرى كه يافتهاى اين تحقيق مبنى بر تأثير تكليف ثانويه مرتبط با مهارت بر دقت برتاب در شرايط انسداد بالا را تأييد

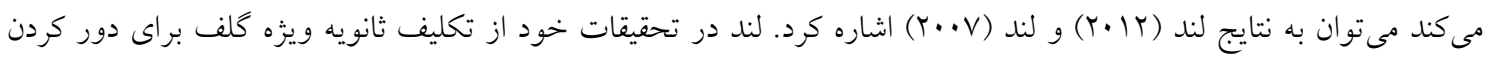

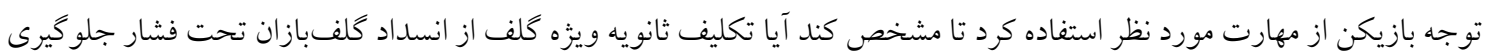
مى كند يا خير. نتايج وى نشان داد كه عملكرد افراد در شرايط تكليف ثانويه مرتبط و نامرتبط با مهارت نسبت به شرايط كنترل بهتر 
است و آنها انسداد كمترى را تجربه مى كند (19). در تحقيق ما نيز هنگام ارايه تكليف ثانويه مرتبط با مهارت، ويزگى فعاليت ورزشى مد نظر قرار كرفت.

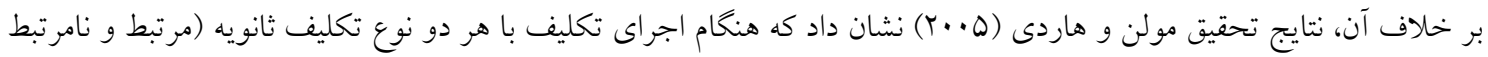

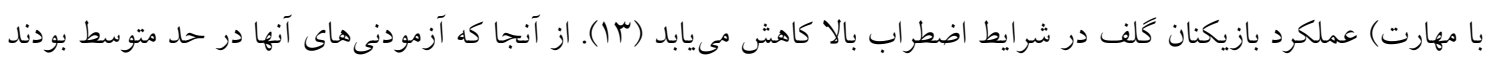

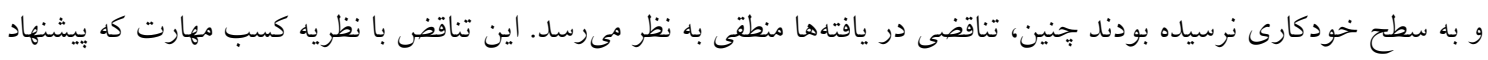

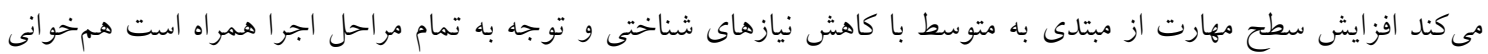

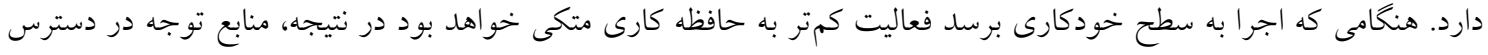

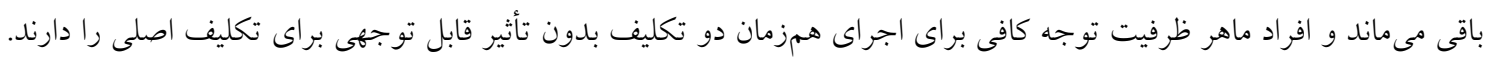

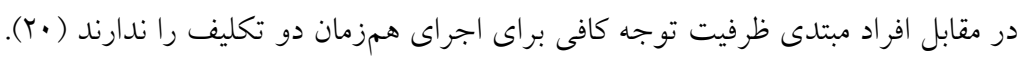

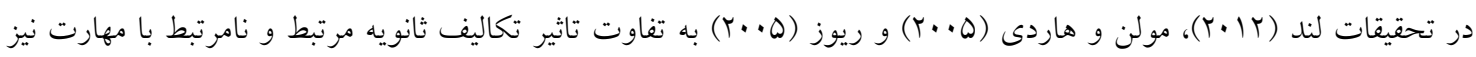

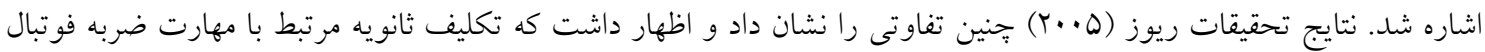

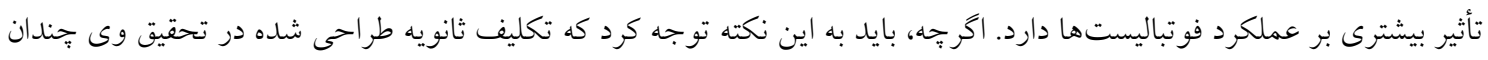

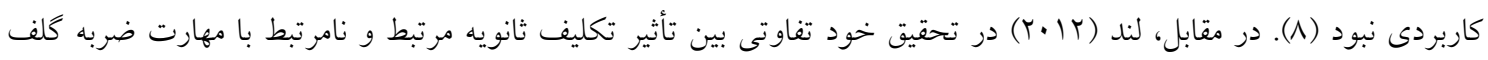

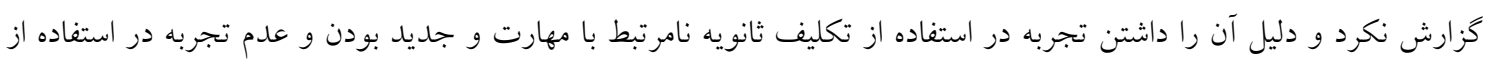

تكليف ثانويه مرتبط با ضربه كلف بيان كرد (19). به طور كلى، يافتهاى تحقيق حاضر نشان داد كه تكليف ثانويه (صرف نظر از مرتبط يا نامرتبط بودن) بهعنوان توجه تمركز بيرونى (1) بانى

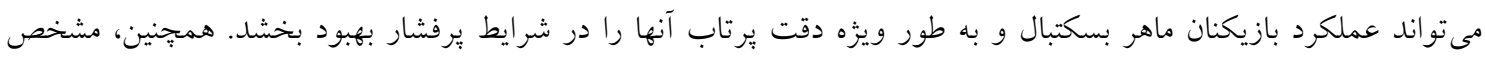

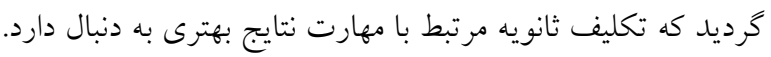

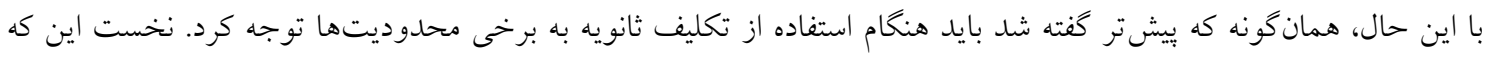

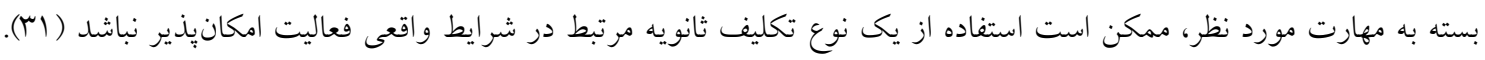

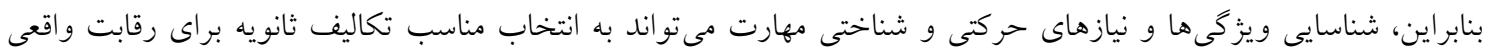

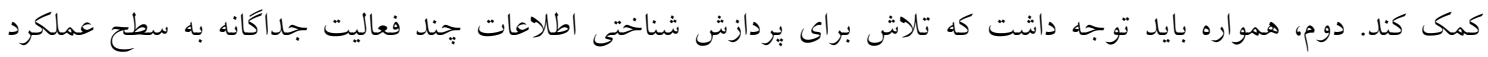

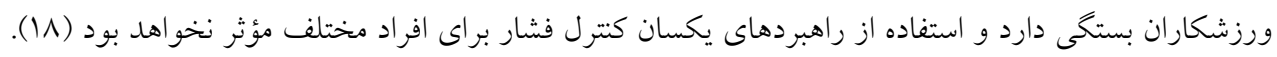

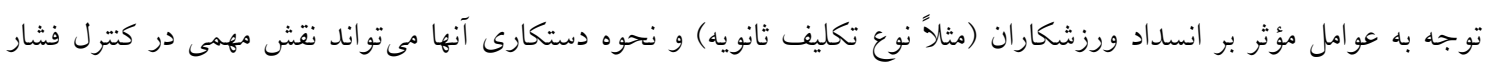

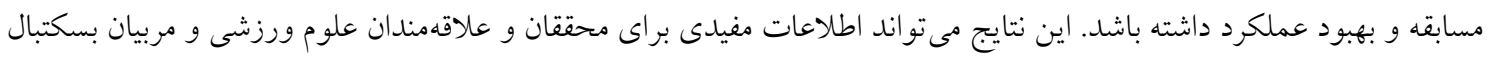

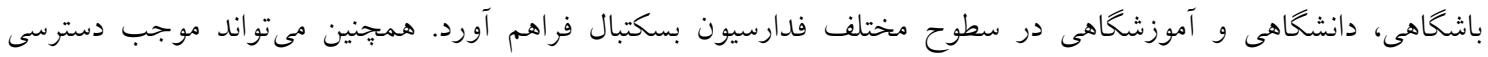

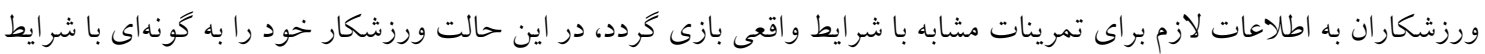

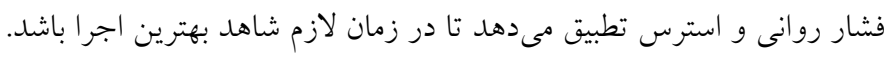

\section{ي بيشنهادات}

بيشنهاد مىشود در تحقيقات بعدى ضمن بررسى تفاوتهاى جنسيتى به ساير تكاليف ثانويه مرتبط با برتاب آزاد بسكتبال توجه شود. علاوه بر اين، ييشنهاد مى شود تكاليف ثانويه كاربردى و مرتبط با ساير مهارتهاى ورزشى طراحى كردد و تكاليف ثانويه از

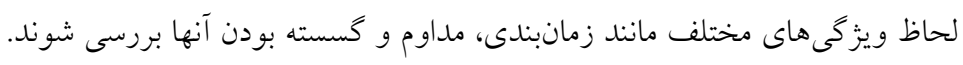
Bewegung und Training, 1(2-3), 1-11.

2. McNevin, N.H., Wulf, G., Carlson, C. (2000). Effects of attentional focus, self-control, and dyad training effects on motor learning: Implications for physical rehabilitation. Physical Therapy, 80, 373-385.

3. Wulf, G., McNevin, N.H., Shea, C.H. (2001). The automaticity of complex motor skill learning as a function of attentional focus. Quarterly Journal of Experimental Psychology, 54A, 1143-1154. 
4. Wulf, G., Shea. C.H., Park, J.H. (2001). Attention in motor learning: Preferences for and advantages of an external focus. Research Quarterly for Exercise and Sport, 72, 335-344.

5. Wulf, G. (2013). Attentional focus and motor learning: a review of 15 years. International Review of Sport and Exercise Psychology, 6(1), 77-104.

6. Bell, J. J., \& Hardy, J. (2009). Effects of attentional focus on skilled performance in golf. Journal of Applied Sport Psychology, 21, 177-163.

7. Fox A. (2010). Choking- its causes and how to minimize its effects. In: Fox, A. editors. Tennis: Winning the mental match. $1^{\text {st }}$ ed. California, Kindle Edition, 52-69.

8. Reeves, J. L. (2005). Attention and performance: When does choking under pressure occur and what is the debilitating source? Unpublished doctoral dissertation, Florida State University, Tallahassee.

9. Jackson, R. C., Ashford, K. J., \& Norsworthy, G. (2006). Attentional focus, dispositional reinvestment and skilled motor performance under pressure. Journal of Sport \& Exercise Psychology, 28, 49-68.

10. Mesagno, C., Marchant, D., \& Morris, T. (2009). Alleviating choking: The sounds of distraction. Journal of Applied Sport Psychology, 21, 131-147.

11. Schmidt, R. A., \& Lee, T.D. (2012). Attention and performance. In R. Schmidt, \& T. Lee (eds.), Motor control and learning: A behavioral emphasis. Champaign, IL: Human Kinetics, 61-91.

12. Beilock, S. L., Carr, T. H., MacMahon, C., \& Starkes, J. L. (2002). When paying attention becomes counterproductive: Impact of divided versus skill-focused attention on novice and experienced performance of sensory motor skills. Journal of Sport Sciences, 20, 271-278.

13. Mullen, R., Hardy, L., \& Tattersall, A. (2005). The effect of anxiety on motor performance: A test of the conscious processing hypothesis. Journal of Sport and Exercise Psychology, 27, 212-225.

14. Ford, P., Hodges, N. J., \& Williams, A. M. (2005). Online attentional focus manipulation in a soccer dribbling task: implication for the proceduralization of motor skill. Journal of Motor Behavior, 37(5), 386394.

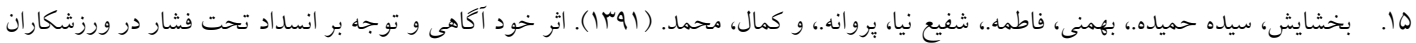

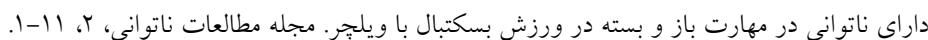

16. Land, W., \& Tenenbaum, G. (2012). An outcome and process oriented examination of a golf-specific secondary task strategy to prevent choking under pressure. Journal of Applied Sport Psychology, 24(3), 303-322.

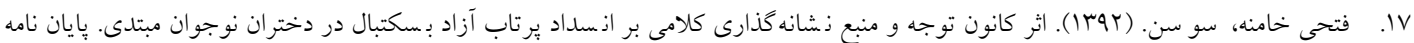

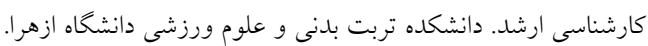

18. Beilock, S. L., Bertenthal, B. I., McCoy, A. M., \& Carr, T. H. (2004). Haste does not always make waste: Expertise, direction of attention, and speed versus accuracy in performing sensorimotor skills. Psychonomic Bulletin \& Review, 11, 373-379.

19. Beilock, S. L. \& Carr, T. H. (2001). On the fragility of skilled performance: What governschoking under pressure? Journal of Experimental Psychology: General, 130, 701-725.

20. Schmidt, R. A., \& Lee, T.D. (2012). Motor control and learning: A behavioral emphasis (5 $5^{\text {th }}$ Ed.). Champaign, IL: Human Kinetics.

21. Clearly, T. (2001). A biomechanics analysis of fatigue compensation in skilled basketball Jump shooters. Journal of Sport Biomechanics, 12(2), 86-95.

22. Raoul, R. D., Oudijanse, R., \& Van De Langenberg, R. I. (2002). Aiming at a far target under different viewing condition: visual control in basketball Jump shooting. Journal of Human movement Sciences, $21,457-480$

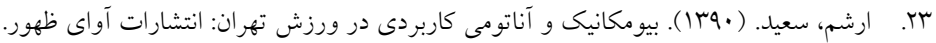

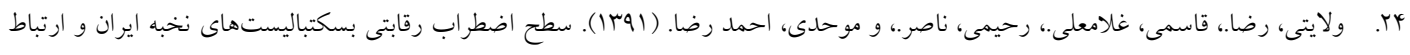

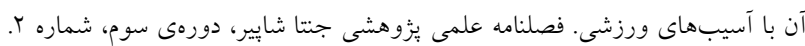

25. Hardy, L., \& Parfitt, C. G. (1991). A catastrophe model of anxiety and performance. British Journal of Psychology, 82, 163-178.

26. Ehrlenspiel, F. (2006). Choking under Pressure-Attention and Motor Control in Performance Situations, master's thesis. Human wissenschaftlichen.

27. Kahneman, D. (1973). Attention and Effort Englewood Cliffs, NJ: prentice Hall.

28. Poolton, J., Maxwell, J. P. Masters, R. S. W., \& Raab, M. (2006). Benefits of an external focus of attention: Common coding or conscious processing? Journal of Sports Sciences. 24, 89-99.

29. Schmidt, R.A., \& Wrisberg, C. A. (2008). Motor learning and performance, a situation-based learning approach (4 ${ }^{\text {th }}$ Ed.). Champaign, IL: Human Kinetics.

30. Welford, A.T. (1952). The psychological refractory period and the timing of high-speed performance: A review and a theory. British Journal of Psychology, 43, 2-19.

31. Castaneda, B., \& Gray, R. (2007). Effects of focus of attention on baseball batting performance in players of differing skill levels. Journal of Sport and Exercise Psychology, 29(1), 60-77. 